\title{
Pesticide resistance in wild mammals - Mechanisms of anticoagulant resistance in wild rodents -
}

\author{
Mayumi Ishizuka', Tsutomu Tanikawa², Kazuyuki D. Tanaka', Min Heewon'1, \\ Fumie Okajima', Kentaro Q. Sakamoto ${ }^{1}$ and Shoichi Fujita ${ }^{1}$ \\ ${ }^{1}$ Laboratory of Toxicology, Graduate School of Veterinary Medicine, Hokkaido University, Sapporo 060-0818, Japan \\ ${ }^{2}$ Technical Research Laboratory, Ikari Corporation, Chiba 260-0844, Japan
}

(Received April 23, 2008)

\begin{abstract}
Warfarin is commonly used worldwide as a rodenticide. It inhibits coagulation of blood by inhibiting vitamin K 2,3-epoxide reductase (VKOR) activity. An inadequate supply of vitamin K blocks the production of prothrombin and causes hemorrhage. It has been reported that repeated or long-term treatments with this drug cause resistance in wild rodents. However, the mechanism of warfarin resistance in rodents is still not known precisely. Recent studies reported and identified the function of the molecule, vitamin $\mathrm{K}$ epoxide reductase complex subunit 1 (VKORC1), which is the main unit of VKOR. An amino acid substitution in VKORC1 is one of the supposed mechanisms of warfarin resistance. An accelerated detoxification system involving cytochrome P450 (CYP) could also cause the rodenticide resistance. Administration of SKF-525A, a potent inhibitor for P450, increased the mortality due to reduction of warfarin metabolism in warfarin-resistant rats. Meanwhile, the appearance of warfarin-resistant rodents has led to the development of the more effective and toxic rodenticide superwarfarin, which is widely used in Europe and the USA. However, animals resistant to this second-generation rodenticide have already been reported in Europe. In this review, we focus on the mechanism and the pleiotropic effects of pesticide resistance in wild rodents.
\end{abstract}

Key words: Warfarin resistance, Rodenticide, Cytochrome P450, Vitamin K epoxide reductase, Rodent

\section{INTRODUCTION}

Brown rats (Rattus norvegicus), roof rats ( $R$. rattus), and house mice (Mus musculus domesticus) live in close proximity to humans. They may carry pathogens of infectious diseases, such as plague, hemorrhagic fever with renal syndrome (HFRS), Weil's disease, hepatitis E, and others. For pest control, rodenticides are the most effective tool, and several types have been developed, e.g., anticoagulants, metal phosphides, erdrin, thallium, fluoroacetamide (1081), and hypercalcemics. Above all, coumarin-derived anticoagulants such as warfarin are commonly used to control rat populations worldwide due to their convenience, safety, and minimal impact on the environment.

Warfarin has been widely and continuously used since the 1950s for pest control. It is well known that frequent insecticide treatments cause resistance in the target insect species. Like insecticides, the repeated use of warfarin has caused drug resistance in wild rodent species. Table 1 shows the appearance locations of warfarin-resistant rodents in the world. Resistance to warfarin was first observed in Scotland in 1958 (Boyle, 1960), and warfarin resistance in the house mouse (M. musculus domesticus) was evident shortly thereafter (Dodsworth, 1961). Since then, resistant rats have been reported all over the world, in Great Britain (Boyle, 1960), Denmark (Lund, 1967), Germany (Telle, 1971), and Belgium (Lund, 1984). Myllymäki (1995) reported resistant rodents in Finland and France. The majority of reports came from Europe, but resistance in commensal rodents was also documented in the USA (Jackson and Kaukeinen, 1972), Canada (Siddiqi and Blaine, 1982), and Australia (Saunders, 1978). These "super rats" are also found around Tokyo, Japan (Naganuma et al., 1981), and warfarin-resistance has led to failure of their control using warfarin as a rodenticide.

However, the precise mechanism of warfarin resistance

Correspondence: Mayumi Ishizuka (E-mail: ishizum@vetmed.hokudai.ac.jp) 
M. Ishizuka et al.

Table 1. Anticoagulant resistance in commensal rats and house mice of the world Modified from Pelz et al. (2005).

\begin{tabular}{|c|c|c|c|c|}
\hline Country & R. norvegicus & R. rattus & $\begin{array}{l}\text { Mus musculus } \\
\text { domesticus }\end{array}$ & $\begin{array}{c}\text { Mutation position in VKORC1 } \\
\text { (rat) }\end{array}$ \\
\hline Belgium & + & & + & 139 \\
\hline Denmark & + & + & + & 139 \\
\hline Finland & & & + & \\
\hline France & + & + & + & 139 \\
\hline Germany & + & + & + & 139,56 \\
\hline United Kingdom & + & + & + & $120,128.139$ \\
\hline Italy & + & & & \\
\hline The Netherlands & + & & + & \\
\hline Sweden & & & + & \\
\hline Switzerland & & & + & \\
\hline Canada & + & & + & \\
\hline United States & + & + & + & \\
\hline Australia & & + & & \\
\hline Japan & & + & & Other than 139 \\
\hline
\end{tabular}

in rodents is still not known. In this review, we focus on the mechanisms of pesticide resistance in rodents.

\section{MUTATION IN TARGET MOLECULE OF WARFARIN}

\section{Vitamin $\mathrm{K}$ cycle and target molecule of warfarin}

The production and activation of coagulation factors VII, IX, $\mathrm{X}$ and prothrombin are dependent on the vitamin $\mathrm{K}$ cycle. Post-translational modification of glutamate to gamma carboxyl glutamate is required for the activity of vitamin K-dependent proteins (Fig. 1) (Stafford, 2005). The carboxylated Glu residue is converted to a Gla amino acid and a reduced vitamin $\mathrm{K}$ molecule is converted to vitamin $\mathrm{K}$ epoxide. Before vitamin $\mathrm{K}$ can be reused in the vitamin $\mathrm{K}$ cycle, vitamin $\mathrm{K}$ epoxide must be converted back to reduced vitamin $\mathrm{K}$ by vitamin $\mathrm{K}$ 2,3-epoxide reductase (VKOR). Recently, Wajih et al. identified the novel endogenous molecules that transfer the electron to VKOR and regenerate the vitamin K cycle (Wajih et al., 2005, 2007).

The pharmacological target of warfarin is VKOR. Through inhibition of VKOR, warfarin blocks the vitamin $\mathrm{K}$ cycle and inhibits the $\gamma$-carboxylation of the vitamin K-dependent blood-clotting factors. An inadequate supply of vitamin K blocks the production of prothrombin and leads to hemorrhaging (Furie and Furie, 1988; Suttie,
1985; Helgeland, 1977; Thijssen et al., 2004; Cain et al., 1998).

\section{Mutation at position of 139 in vitamin $\mathrm{K}$ epoxide reductase}

Thijssen et al. (1989) reported that VKOR activity in liver microsomes of resistant rats was not inhibited by warfarin. They also reported that the basal VKOR activity in warfarin-resistant rats was remarkably lower than that of warfarin-sensitive animals. Thus, a mutation of the VKOR gene and conformation of the protein structure is a possible mechanism of warfarin resistance.

In 2004, two research groups identified and reported a novel molecule that contributes to VKOR activity in the rat and named it vitamin $\mathrm{K}$ epoxide reductase complex subunit 1 (VKORC1) (Rost et al., 2004; Li et al., 2004). VKORC1 is an $18 \mathrm{kDa}$ hydrophobic protein resident in the endoplasmic reticulum membrane. Hydrophobicity plots and secondary structure predictions suggest a topology of VKORC1 protein that includes 3 to $4 \alpha$-helical transmembrane segments (Goodstadt and Ponting, 2004). In the first report on VKORC1, Rost et al. (2004) suggested that warfarin resistance in rats was attributable to the Tyr139Phe mutation in the VKORC1 gene. Then it was shown that the C132-X-X-C135 motif in VKO$\mathrm{RC} 1$ comprises part of the site of redox activity that catalyzes the vitamin $\mathrm{K}$ epoxide reduction (Rost et al. 2005; 


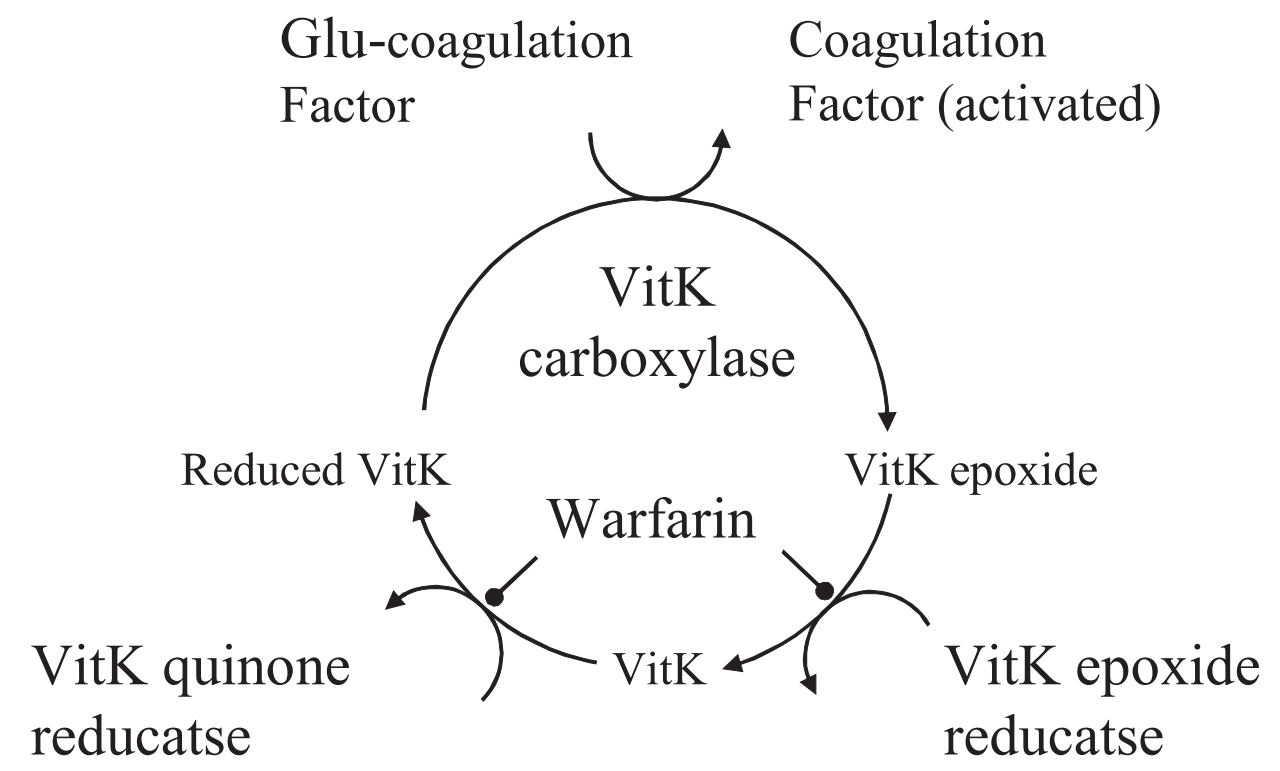

Fig. 1. Warfarin inhibits the vitamin K cycle. Vitamin K epoxide reductase (VKOR) activity is suppressed by warfarin exposure. Inhibition of VKOR produces abnormal coagulation factor and causes fatal hemorrhage. VitK: vitamin K.

Goodstadt and Ponting, 2004). Rost et al. also suggested a crucial role for the hydrophobic Thr-Tyr-Ala motif in coumarin binding.

Pelz et al. (2005) showed the current status of anticoagulant resistance in commensal rats and house mice in Europe. The codon positions at Arg35Pro, Ser56Pro, Leu120Gln, Leu128Gln, and Thr139Phe were indicated to be responsible for warfarin resistance (Table 1). In European rats, and especially, the substitution at the 139 codon position is the most common and potent candidate for resistance to warfarin. They also reported that the Thr139Phe amino acid substitution caused the greatest resistance of VKOR activity toward warfarin when this mutated enzyme was expressed in HEK 293 cells (Pelz et al., 2005).

\section{Compensatory molecule for loss of VKOR in warfarin-resistant rats}

The VKORC1 139 mutation in warfarin-resistant rats causes a structural conformation of the VKORC1 protein, and this conformation prevents warfarin blocking (Rost et al., 2005). In addition to resistance to warfarin, this mutation may cause a dysfunction or drastic suppression of vitamin $\mathrm{K}$ epoxide reduction and induce compensatory mechanisms to maintain blood clotting. The VKOR activity of warfarin-resistant animals is drastically lower than that of normal animals, and how warfarin-resistant rats survive with markedly low or almost non-existent VKOR activity has been an unanswered question. Although the system that supports the loss of VKOR activity via the VKORC1 molecule is still unclear, one possible mechanism to explain the survival of warfarin-resistant rats under the condition of defective VKOR activity is resupply of exogenous vitamin $\mathrm{K}$ in resistant rodents (Markussen et al., 2003).

Warfarin resistance has been often shown to be associated with unexpected effects, particularly with an increased dietary requirement for vitamin K. Markussen et al. (2003) reported a moderately increased requirement for vitamin K in Danish homozygous rats resistant to warfarin compared to heterozygous resistant rats.

Heiberg et al. (2006) showed that moderately warfarin-resistant females were better breeders than highly resistant females in the environmental condition without anticoagulant selection. They suggested that in males highly tolerant to rodenticides, the selection presumably takes place at the immature stage, whereas in females the vitamin $\mathrm{K}$ requirement becomes crucial at the reproductive stage because vitamin $\mathrm{K}$ is not only essential for the blood clotting process but also for bone formation. The drastically suppressed vitamin $\mathrm{K}$ production in highly tolerant females might not be able to support the reproductive function. Thus, heterozygous resistant females, which have a much lower vitamin $\mathrm{K}$ requirement, will dominate 
the reproduction in resistant rats (Heiberg et al., 2006). They pointed out that the disadvantage of vitamin $\mathrm{K}$ deficiency in anticoagulant-resistant rats during reproduction may be useful information for pest control.

\section{Kinetics analyses of VKOR in warfarin-resistant and -sensitive brown rats}

Although further study is needed to clarify how anticoagulant-tolerant rats survive with markedly reduced VKOR activity and acquire warfarin resistance at the same time, Lasseur et al. showed one reasonable hypothesis for this problem.

Lasseur et al. (2006) reported that warfarin resistance in brown rats in France was attributable to a mutation (Tyr139Phe) in VKORC1. The mutation at position 139, which is supposed to be one of the warfarin-binding sites, caused low VKOR activity (low $V_{\text {max }}$ ) in warfarin-resistant brown rats. However, a very low $K_{m}$ of VKOR activity in the French warfarin-resistant rats led to equal or even higher enzymatic efficiency $\left(V_{\max } / K_{m}\right)$ than in warfarin-sensitive rats. Thus, Lasseur et al. showed that at physiologically low concentrations of the substrate (vitamin $\mathrm{K}$ epoxide), the substituted VKORC1 molecule can supply high enough levels of reduced vitamin $\mathrm{K}$ to allow the vitamin K cycle to function.

\section{Kinetics analyses of VKOR in warfarin-resistant and -sensitive mice}

In addition to the rat VKOR, Lasseur et al. also determined the kinetic parameters of warfarin-resistant mice (M. musculus domesticus) (Lasseur et al., 2006). They suggested that warfarin resistance in mice was related to both metabolic modification and mutations in the VKORC1 gene as in the warfarin-resistant rat. In their report, they suggested that the enzymatic model was composed of two components. The first component A corresponds to a low affinity but high capacity, and the second component $\mathrm{B}$ corresponds to a high affinity but low capacity. They estimated that component A is very sensitive to warfarin and that B appears to be more resistant, requiring 20-30 fold higher $K i$ values.

However, the reason why the mice acquired resistance to warfarin was unanswered in their report, because there was no clear difference between the kinetic parameters of components A and B of susceptible and resistant mice. The enzymatic efficiency of $V_{\max } / K_{m}$ was lower in warfarin-resistant than that in -susceptible mice, unlike the previous report on rats (Lasseur et al., 2006). The $K i$ values were similar in warfarin-resistant and -sensitive animals. Thus, mutations in VKORC1 alone cannot explain all aspects of resistance in this rodent.

\section{Vitamin K-dependent Y-carboxylation system}

The vitamin K-dependent $\gamma$-carboxylation system is located in the endoplasmic reticulum. The system modifies vitamin $\mathrm{K}$-dependent proteins post-translationally by adding an extra carboxyl group onto the carbon of specific Glu residues normally located in the N-terminal part of the protein. This modification converts Glu residues to Gla residues, which bind calcium (Suttie, 1985).

Wallin et al. focused on the vitamin K-dependent $\gamma$ carboxylation system because they did not find mutations in VKORC1 in warfarin-resistant rodents (Wallin and Hutson, 2004). Wallin showed that the calumenin expression level was higher in resistant rats than in sensitive rats. They also demonstrated that overexpression of calumenin inhibits the warfarin inhibition of VKOR-dependent activity (Wallin et al., 2001).

\section{WARFARIN METABOLISM IN RESISTANT RODENTS}

\section{Cytochrome P450}

Several forms of cytochrome P450 (CYP) are known to metabolize warfarin (Daly et al., 2003). CYP enzymes comprise a superfamily of monooxygenases and are present in many tissues. The CYP-dependent monooxygenase system plays a central role in oxidative metabolism or biotransformation of a wide range of compounds (Werck-Reichhart and Feyereisen, 2000). CYP can metabolize numerous endogenous compounds such as steroids, bile acids, fatty acids, and prostaglandins. In addition to endogenous substrates, CYP is also one of the most important enzymes to eliminate foreign chemicals, e.g., drugs, chemical carcinogens, and environmental pollutants (Nebert and Russell, 2002). NADPH cytochrome $\mathrm{P} 450$ reductase can transfer the electrons needed by CYPs for the catalytic cycle. Metabolically transformed foreign compounds are conjugated with larger endogenous molecules with the aid of different families of transferase enzymes (e.g., glutathione $S$-transferase and UDP glucuronosyltransferase) (Hayes et al., 2005; Guillemette, 2003).

The CYP gene sequences, mapping, accession numbers, and nomenclature of the sequenced members of this superfamily recently have been updated by the Cytochrome P450 Nomenclature Committee, and most recently by Nelson et al. (http://drnelson.utmem.edu/CytochromeP450.html). The human genome contains 57 genes for cytochrome P450 enzymes (Nelson, 2004). In the case of rats, 88 CYP genes and 69 CYP pseudogenes were found in the genome sequence. 
pesticide resistance in wild rodents

\section{Warfarin metabolism}

In humans, anticoagulation therapy with warfarin has traditionally posed a challenge to clinicians. Warfarin is a racemic mixture of two enantiomers, the $(R)$ and $(S)$ forms, and the warfarin $(S)$-enantiomer is 3-5 times more potent than the $(R)$-enantiomer (Kaminsky and Zhang, 1997). The human CYP2C9 enzyme contributes to about $80 \%$ of the metabolism of the $(S)$-enantiomer of warfarin to 7-hydroxywarfarin. Several studies also suggest that a CYP2C9 variant allele is associated with an increased risk of adverse reactions to warfarin in humans (Kirchheiner and Brockmöller, 2005). The (R)-enantiomer is metabolized to 6-, 7-, 8-, and 10-hydroxywarfarin by several CYP isoforms including CYP1A2, CYP3A4, and CYP2C19 in humans (Kaminsky and Zhang, 1997). The CYP2C19 activity supposed to be important in the pharmacokinetics of $(R)$-warfarin (Uno et al., 2008).

In rats, warfarin hydroxylations are mainly catalyzed by CYP2C, CYP2B, CYP1A, and CYP3A subfamilies (Fig. 2). The five hydroxides are identified as 4'-, 6-, 7-, 8- or 10-OH warfarin in rats (Guengerich et al., 1982), and these primary metabolites are made more water-soluble by UDP-glucuronyltransferase activity and excreted in urine, as in the metabolic pathway in humans.

\section{Modification of warfarin metabolism in resistant rats}

Sugano et al. (2001) newly reported the potent resistance of wild roof rats in the Tokyo area of Japan to warfarin. They focused on the low level of mRNA expression of the warfarin-metabolizing enzyme CYP3A, which catalyzes warfarin 10-hydroxylation in resistant rats, and concluded that reduced metabolic activation of warfarin might cause the resistance. However, it has been reported that CYP3A induction by St. John's wort decreases the anticoagulant effect and increases the tolerance for higher doses of warfarin in humans (Izzo, 2005). In addition, actually, the protein expression levels of CYP3A were higher in liver microsomes from warfarin-resistant roof rats than those from -sensitive animals (Ishizuka et al., 2007)

In insects, elevation of the ability to detoxify foreign chemicals by the induction of enzyme expression or genetic-polymorphism allows them to adapt to an insecticide-contaminated environment (Scott, 1999). In mammals, exposure to environmental pollutants such as pesticides might be the fatal stress for a small species. Thus, to adapt to the polluted environment, it is possible that induction of the expression of CYP isoforms accelerates detoxification in wild rodents after the exposure to these

\section{Warfarin}

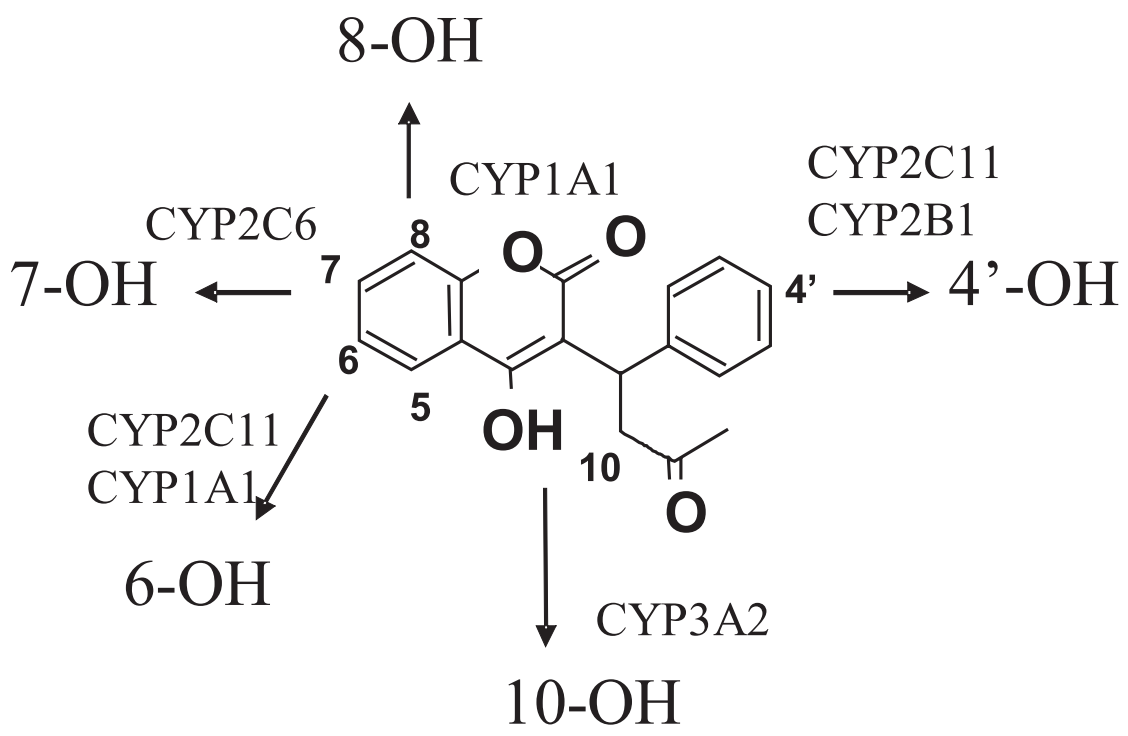

Fig. 2. Warfarin metabolic pathways in liver of male rat. Warfarin is a typical P450 substrates, and CYP1A1, 2B1, 2C6, 2C11, and $3 \mathrm{~A} 2$ contribute to warfarin metabolism. 
pesticides.

In a previous study, warfarin levels in plasma were lower in warfarin-resistant than in -sensitive animals after warfarin administration (Ishizuka et al., 2007). Warfarin metabolic activities in resistant rats were higher than those of sensitive animals. In addition, NADPH cytochrome c reductase activity dependent on NADPH cytochrome $\mathrm{P} 450$ reductase was markedly higher in resistant rats than in sensitive rats. This may be the reason for high activities in every pathway of warfarin metabolism in resistant rats. To establish the contribution of P450 to warfarin resistance, resistant roof rats were treated with feed containing warfarin and a potent CYP inhibitor, SKF-525A (Ishizuka et al., 2007). The increased rate of mortality in rats co-treated with warfarin and SKF-525A indicated the possibility that CYP-dependent warfarin metabolism might contribute to warfarin resistance in wild rodents. It was concluded that the elevation of P450-dependent warfarin metabolism also gave rise to warfarin resistance in wild rats.

\section{SUPERWARFARIN AGAINST RESISTANT RODENTS}

\section{New generation of anticoagulants}

More than 60 years ago, the discovery that dicoumarol was the causative agent of haemorrhagic disease in cattle fed spoiled sweet clover hay spurred the development of the 4-hydroxycoumarins. This led to the discovery of warfarin as a rodenticide.

Now, due to the resistance to warfarin in wild rodents, a new generation of anticoagulants has been developed (Petterino and Paolo, 2001; Gebauer, 2007). The new toxic warfarins are called superwarfarins, and are categorized in two groups: 4-hydroxycoumarins (e.g., brodifacoum, bromodialone, and difenacoum) and the inadione derivatives (e.g., diphacinone and chlorphacinone) (World Health Organization, 1995). Like warfarin, the target molecule of these superwarfarins is vitamin $\mathrm{K}$ epoxide reductase. Superwarfarins are toxins characterized by an extremely long half-life and a potent fatal activity comparable to warfarin. Superwarfarin has already been marketed in over-the-counter rodenticides.

This potent toxic superwarfarin has been used worldwide to effectively control rats. However, there are two problems to note in the continuous use of superwarfarin for pest control, as follows.

\section{Poisoning of non-target species}

The first point is the recent increase in superwarfarin poisoning in non-target animals, including humans (Ayala et al., 2007; Spahr et al., 2007; Stone et al., 1999; Kotsaftis et al., 2007). Especially, superwarfarin has caused primary and secondary poisonings of wild birds.

Rodenticides were used to eradicate invasive rodents on islands in New Zealand. However, the use of superwarfarin for the eradiation of invasive rodent populations on islands caused a drastic reduction in the number of wild birds (Johnston et al., 2005; Eason et al., 2001). As shown in Table 2, superwarfarin possessed potent toxicity not only in rodents but also non-target species (Petterino and Paolo, 2001).

\section{Resistance against second-generation rodenticide}

The second point of concern is the possibility of the appearance and distribution of resistance against superwarfarin in the rats surviving frequent superwarfarin exposures. Already, many single nucleotide polymorphisms (SNPs) in rat VKORC1 have been reported around Europe, which are suggested to cause resistance to rodenticdes (Pelz et al., 2005). In addition, elevation of the ability to detoxify foreign chemicals due to the induction of enzyme expression or genetic-polymorphism in wild rodents may allow them to adapt to a rodenticidecontaminated environment. Exposures to environmental pollutants such as pesticides might induce the expression of P450 isoforms in wild rodents to accelerate detoxification, as shown in the report on the Tokyo resistant rat (Ishizuka et al., 2007). Fujita et al. (2001) also report-

Table 2. Comparative toxicology of warfarin in rat and birds

\begin{tabular}{cccc}
\hline Species & $\begin{array}{c}\text { Brodifacoum } \\
\text { (second generation } \\
\text { hydroxycoumarin) }\end{array}$ & $\begin{array}{c}\text { Difethialone } \\
\text { (second generation } \\
\text { hydroxycoumarin) }\end{array}$ & $\begin{array}{c}\text { Diphacinone } \\
\text { (inadione derivative) }\end{array}$ \\
\hline rat & 0.27 & 0.56 & 2.3 \\
bird & $\begin{array}{c}\text { C.31 (Mallard duck) } \\
\text { hydroxycoumari) }\end{array}$ & 0.264 (bobwhite quail) & 3158 (Mallard duck) \\
\hline
\end{tabular}

The values were LD50 (mg/kg) in rat and bird species. The data were modified from Petterino and Paolo (2001). 
pesticide resistance in wild rodents

ed on the elevation of CYP2B and CYP3A expressions in wild voles (Clethrionomys rufocanus) that inhabited highly pesticide-contaminated areas. Alternatively, polymorphically higher expression of CYP may enhance the ability of detoxification. Hoshi et al. (1995) found a polymorphic P450 isoform (CYP2D) in wild rodents, and reported extensive and poor metabolizers of xenobiotics. In the future, it is possible that the continuous and potent fatal stress by abuse of superwarfarin willause the selection of adaptive gene(s) and lead to distribution of the second "super rat". Already rats resistant to the toxicity of the second-generation rodenticide have been found in areas of Europe (Kohn et al., 2000, 2003).

\section{PERSPECTIVES ON THE FUTURE}

The evolutional adaptation of mammals to a polluted environment is very interesting because these phenomena are usually observed in short-lived invertebrate species such as insects. Recently, we found novel warfarinresistant brown rats in several areas of Japan in addition to the roof rats in the Tokyo area (data not shown). There were individual differences in the resistance potency to warfarin. We have analyzed the VKORC1 gene seqnences, and VKOR and CYP-dependent metabolism in warfarin-resistant Tokyo roof rats and novel resistant brown rats from other areas in Japan. We did not find any substitutions at codon 139 in the Japanese warfarin-resistant rats. Thus, we now suggest that the mechanism of warfarin resistance may not arise simply from the VKORC1 139 mutation alone, but may vary according to the area of habitation (or environment). We also suggest the possibility of mixed mechanisms of warfarin resistance, e.g., modulations in both VKOR and CYP-dependent systems (Fig. 3). In addition, several types of rodents tolerant to anticoagulant rodenticides might acquire the ability to resupply vitamin $\mathrm{K}$ outside the VKOR-dependent cycle. We expect that studies of the novel resistant rodent will clarify these points in the future.

The next step in pest control has usually been to switch to a more powerful and effective substance when resistance appears in a colony of animals. However, clarifica-

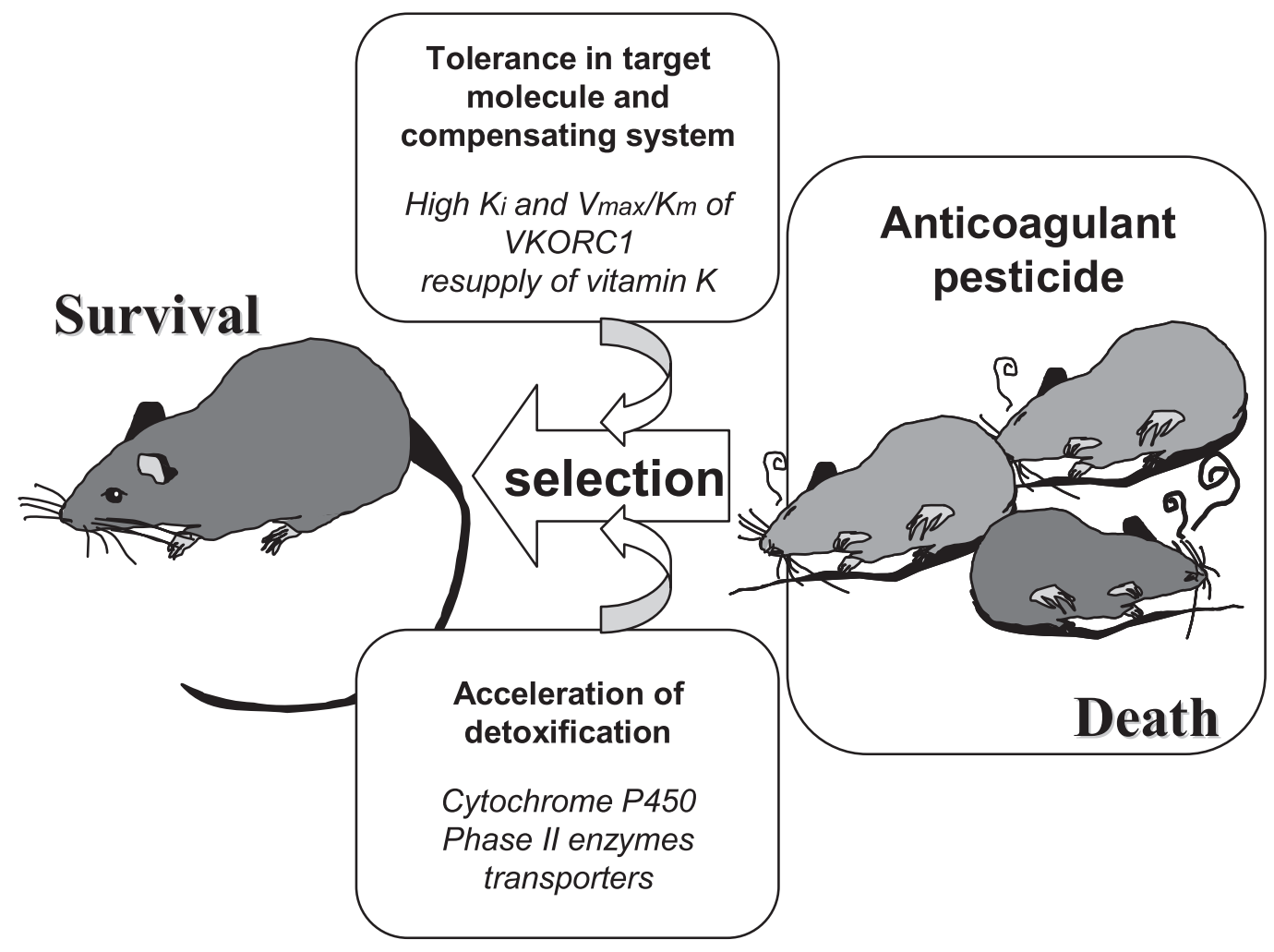

Fig. 3. Mechanisms for resistance against anticoagulant rodenticides. It is possible that several mechanisms contribute to warfarin resistance, e.g., modulations of both VKOR and CYP-dependent systems. 
tion of the detailed mechanisms of rodenticide tolerance may establish a new approach to using rodenticides for pest control.

\section{ACKNOWLEDGMENTS}

We thank Mr. Tsunehito Harunari (Technical Research Laboratory, Ikari Corporation) for his assistance to this study. This study was partly supported by Grants-in-Aid for Scientific Research from the Ministry of Education, Culture, Sports, Science and Technology of Japan awarded to S. Fujita (No. 19208028) and M. Ishizuka (No. 19671001).

\section{REFERENCES}

Ayala, I., Rodríguez, M.J., Martos, N., Zilberschtein, J., Ruíz, I. and Motas, M. (2007): Fatal brodifacoum poisoning in a pony. Can. Vet. J., 48, 627-629.

Boyle, C.M. (1960): Case of apparent resistance of Rattus norvegicus Berkenhout to anticoagulant poisons. Nature, 188, 517-525.

Cain, D., Hutson, S.M. and Wallin, R. (1998): Warfarin resistance is associated with a protein component of the vitamin K 2,3-epoxide reductase enzyme complex in rat liver. Thromb. Haemostasis, 80, 128-133.

Dodsworth, E. (1961): Mice are spreading despite such poisons as warfarin. Minic. Engin. Lond., 3746, 1668.

Eason, C.T., Murphy, E.C., Wright, G.R.G. and Spurr, E.B. (2001): Assessment of Risks of Brodifacoum to Non-target Birds and Mammals in New Zealand. Ecotoxicology, 11, 35-48.

Fujita, S., Chiba, I., Ishizuka, M., Hoshi, H., Iwata, H., Sakakibara, A., Tanabe, S., Kazusaka, A., Masuda, M., Masuda, Y. and Nakagawa, H. (2001): P450 in wild animals as a biomarker of environmental impact. Biomarkers, 6, 19-25.

Furie, B. and Furie, B.C. (1988): The molecular basis of blood coagulation. Cell, 53, 505-518

Gebauer, M. (2007): Synthesis and structure-activity relationships of novel warfarin derivatives. Bioorg. Med. Chem., 15, 24142420 .

Goodstadt, L. and Ponting, C.P. (2004): Vitamin K epoxide reductase: homology, active site and catalytic mechanism. Trends Biochem. Sci., 29, 289-292.

Guengerich, F.P., Dannan, G.A., Wright, S.T., Martin, M.V. and Kaminsky, L.S. (1982): Purification and characterization of liver microsomal cytochromes p-450: Electrophoretic, spectral, catalytic, and immunochemical properties and inducibility of eight isozymes isolated from rats treated with phenobarbital or betanaphthoflavone. Biochemistry, 21, 6019-6030.

Guillemette, C. (2003): Pharmacogenomics of human UDP-glucuronosyltransferase enzymes. Pharmacogenomics J., 3, 136158.

Hayes, J.D., Flanagan, J.U. and Jowsey, I.R. (2005): Glutathione transferases. Annu. Rev. Pharmacol. Toxicol., 45, 51-88.

Heiberg, A.C., Leirs, H. and Siegismund, H.R. (2006): Reproductive success of bromadiolone-resistant rats in absence of anticoagulant pressure. Pest Manag. Sci., 62, 862-871.

Helgeland, L. (1977): The submicrosomal site for the conversion of prothrombin precursor to biologically active prothrombin in rat liver. Biochim. Biophys. Acta., 499, 181-193.

Hoshi, H., Masuda, M., Yamamoto, Y., Suimamoto, Y., Kazusaka, A. and Fujita, S. (1995): Debrisoquine/sparteine-type polymorphic drug metabolism in wild Clethrionomys rufocanus. Drug Metab. Dispos., 23, 1301-1303.

Ishizuka, M., Okajima, F., Tanikawa, T., Min, H., Tanaka, K.D., Sakamoto, K.Q. and Fujita, S. (2007): Elevated warfarin metabolism in warfarin-resistant roof rats (Rattus rattus) in Tokyo. Drug Metab. Dispos., 35, 62-66.

Izzo, A.A. (2005): Herb-drug interactions: An overview of the clinical evidence. Fundam. Clin. Pharmacol., 19, 1-16.

Jackson, W. and Kaukeinen, D. (1972): Resistance of wild Norway rats in North Carolina to warfarin rodenticide. Science, 176, 1343-1344.

Johnston, J.J., Pitt, W.C., Sugihara, R.T., Eisemann, J.D., Primus, T.M., Holmes, M.J., Crocker, J. and Hart, A. (2005): Probabilistic risk assessment for snails, slugs, and endangered honeycreepers in diphacinone rodenticide baited areas on Hawaii, USA. Environ. Toxicol. Chem., 24, 1557-1567.

Kaminsky, L.S. and Zhang, Z.Y. (1997): Human P450 metabolism of warfarin. Pharmacol. Ther., 73, 67-74.

Kirchheiner, J. and Brockmöller, J. (2005): Clinical consequences of cytochrome P450 2C9 polymorphisms. Clin. Pharmacol. Ther., 77, 1-16.

Kohn, M.H., Pelz, H.J. and Wayne, R.K. (2000): Natural selection mapping of the warfarin-resistance gene. Proc. Natl. Acad. Sci. USA., 97, 7911-7915.

Kohn, M.H., Pelz, H.J. and Wayne, R.K. (2003): Locus-specific genetic differentiation at Rw among warfarin-resistant rat (Rattus norvegicus) populations. Genetics, 164, 1055-1070.

Kotsaftis, P., Girtovitis, F., Boutou, A., Ntaios, G. and Makris, P.E. (2007): Haemarthrosis after superwarfarin poisoning. Eur. J. Haematol., 79, 255-257.

Lasseur, R., Grandemange, A., Longin-Sauvageon, C., Berny, P. and Benoit, E. (2006): Heterogeneity of the coumarin anticoagulant targeted vitamin K epoxide reduction system. Study of kinetic parameters in susceptible and resistant mice (Mus musculus domesticus). J. Biochem. Mol. Toxicol., 20, 221-229.

Lasseur, R., Longin-Sauvageon, C., Videmann, B., Billeret, M., Berny, P. and Benoit, E. (2006): Warfarin resistance in a French strain of rats. J. Biochem. Mol. Toxicol., 19, 379-385.

Li, T., Chang, C.Y., Jin, D.Y., Lin, P.J., Khvorova, A. and Stafford, D.W. (2004): Identification of the gene for vitamin K epoxide reductase. Nature. 427, 541-544.

Lund, M. (1967): The resistance to anticoagulants. Dan. Pest. Infest. Lab., 47, 611-618.

Lund, M. (1984): Resistance to the second-generation anticoagulant rodenticides. Proc. Vertebrate Pest. Conf., 11, 89-94.

Markussen, M.D., Heiberg, A.C., Nielsen, R. and Leirs, H. (2003): Vitamin K requirement in Danish anticoagulant-resistant Norway rats (Rattus norvegicus). Pest. Manag. Sci., 59, 913-920.

Myllymäki, A. (1995): Anticoagulant resistance in Europe: appraisal of the data from the 1992 EPPO questionnaire. Pesticide Sci., 43, 69-72.

Naganuma, K., Fujita, A., Taniguchi, N. and Takada, S. (1981): Warfarin susceptibility in the roof rat, Rattus rattus, in some locations of Tokyo. Jap. J. Sanit. Zool., 32, 243-245.

Nebert, D. and Russell, D. (2002): Clinical importance of the cytochromes P450. Lancet, 360, 1155-1162.

Nelson, D.R., Zeldin, D.C., Hoffman, S.M., Maltais, L.J., Wain, H.M. and Nebert, D.W. (2004): Comparison of cytochrome P450 (CYP) genes from the mouse and human genomes, includ- 
pesticide resistance in wild rodents

ing nomenclature recommendations for genes, pseudogenes and alternative-splice variants. Pharmacogenetics, 14, 1-18.

Pelz, H.J., Rost, S., Hunerberg, M., Fregin, A., Heiburg, A.C., Baert, K., MacNicoll, A.D., Prescott, C.V., Walker, A.S., Oldenburg, J. and Müller, C.R. (2005): The genetic basis of resistance to anticoagulants in rodents. Genetics, 170, 1839-1847.

Petterino, C. and Paolo, B. (2001): Toxicology of various anticoagulant rodenticides in animals. Vet. Hum. Toxicol., 43, 353-360.

Rost, S., Fregin, A., Ivaskevicius, V., Conzelmann, E., Hörtnagel, K., Pelz, H.J., Lappegard, K., Seifried, E., Scharrer, I., Tuddenham, E.G.D., Müller, C.R., Strom, T.M. and Oldenburg, J. (2004): Mutations in VKORC1 cause warfarin resistance and multiple coagulation factor deficiency type 2. Nature, 427, 537-541.

Rost, S., Fregin, A., Hünerberg, M., Bevans, C.G., Müller, C.R. and Oldenburg, J. (2005): Site-directed mutagenesis of coumarintype anticoagulant-sensitive VKORC1: evidence that highly conserved amino acids define structural requirements of enzymatic activity and inhibition by warfarin. Thromb. Haemost., 94, 780-786.

Saunders, G.R. (1978): Resistance to warfarin in the roof rat in Sydney. NSW Search, 9, 39-40.

Scott, J.G. (1999): Cytochromes P450 and insecticide resistance. Insect. Biochem. Molec. Biol., 29, 757-777.

Siddiqi, Z. and Blaine, W.D. (1982): Anticoagulant resistance in house mice in Toronto, Canada Environ. Health Rev., 32, 49-51.

Spahr, J.E., Maul, J.S. and Rodgers, G.M. (2007): Superwarfarin poisoning: a report of two cases and review of the literature. Am. J. Hematol., 82, 656-660.

Stafford, D.W. (2005): The vitamin K cycle. J. Thromb. Haemost., 3, $1873-1878$.

Stone, W.B., Okoniewski, J.C. and Stedelin, J.R. (1999): Poisoning of wildlife with anticoagulant rodenticides in New York. J. Wildl. Dis., 35, 187-193.

Sugano, S., Kobayashi, T., Tanikawa, T., Kawakami, Y., Kojima, H., Nakamura, K., Uchida, A., Morishima, N. and Tamai, Y. (2001): Suppression of CYP3A2 mRNA expression in the warfarinresistant roof rat, Rattus rattus: Possible involvement of cyto- chrome P450 in the warfarin-resistance mechanism. Xenobiotica, 31, 399-407.

Suttie, J.W. (1985): Vitamin K-dependent carboxylase. Annu. Rev. Biochem., 54, 459-477.

Telle, H. (1971): Resistance to warfarin of the brown rat Rattus norvregicus in Germany. WHO Bull., 45, 331-334.

Thijssen, H.H., Janssen, C.A. and Mosterd, J.J. (1989): Warfarin resistance: biochemical evaluation of a warfarin-resistant wild brown rat. Biochem. Pharmacol., 38, 3129-32.

Thijssen, H.H., Soute, B.A., Vervoort, L.M. and Claessens, J.G. (2004): Paracetamol (acetaminophen)-warfarin interaction: NAPQ1, the toxic metabolite of paracetamol, is an inhibitor of enzymes in the vitamin K cycle. Thromb. Haemost., 92, 797802.

Uno, T., Sugimoto, K., Sugawara, K. and Tateishi, T. (2008): The effect of CYP2C19 genotypes on the pharmacokinetics of warfarin enantiomers. J. Clin. Pharm. Ther., 33, 67-73.

Wajih, N., Hutson, S.M. and Wallin, R. (2007): Disulfide-dependent protein folding is linked to operation of the vitamin $\mathrm{K}$ cycle in the endoplasmic reticulum. A protein disulfide isomerase-VKO$\mathrm{RC} 1$ redox enzyme complex appears to be responsible for vitamin K1 2,3-epoxide reduction. J. Biol. Chem., 282, 2626-2635.

Wajih, N., Sane, D.C., Hutson, S.M. and Wallin, R. (2005): Engineering of a recombinant vitamin K-dependent gamma-carboxylation system with enhanced gamma-carboxyglutamic acid forming capacity: evidence for a functional CXXC redox center in the system. J. Biol. Chem., 280, 10540-10547.

Wallin, R., Hutson, S.M., Cain, D., Sweatt, A. and Sane, D.C. (2001): A molecular mechanism for genetic warfarin resistance in the rat. FASEB J., 15, 2542-2544.

Wallin, R. and Hutson, S.M. (2004): Warfarin and the vitamin Kdependent gamma-carboxylation system. Trends Mol. Med., 10, 299-302.

Werck-Reichhart, D. and Feyereisen, R. (2000): Cytochromes P450: a success story. Genome Biol., 1, REVIEWS3003.

World Health Organization. (1995): Anticoagulant rodenticides. Environmental Health Criteria, 175. 